\title{
Providing Integrated Total Catch Advice for the Management of Mixed Fisheries with an Eco-viability Approach
}

\author{
Florence Briton $^{1}$ (i) . Claire Macher ${ }^{1}$ (D) . Mathieu Merzeréaud ${ }^{1} \cdot$ Christelle Le Grand $^{1} \cdot$ Spyros Fifas $^{2}$. \\ Olivier Thébaud ${ }^{1}$
}

Received: 7 January 2019 / Accepted: 18 October 2019 / Published online: 26 November 2019

(C) The Author(s) 2019

\begin{abstract}
Well-established single-species approaches are not adapted to the management of mixed fisheries where multiple species are simultaneously caught in unselective fishing operations. In particular, ignoring joint production when setting total allowable catches (TACs) for individual species is likely to lead to over-quota discards or, when discards are not allowed, to lost fishing opportunities. Furthermore, economic and social objectives have been poorly addressed in the design of fisheries harvest strategies, despite being an explicit objective of ecosystem-based fisheries management in many jurisdictions worldwide. We introduce the notion of operating space as the ensemble of reachable, single-species fishing mortality targets, given joint production in a mixed fishery. We then use the concept of eco-viability to identify TAC combinations which simultaneously account for multiple objectives. The approach is applied to the joint management of hake and sole fishing in the Bay of Biscay, also accounting for catches of Norway lobster, European seabass and anglerfish. Results show that fishing at the upper end of the MSY range for sole and slightly above Fmsy for hake can generate gains in terms of long-term economic viability of the fleets without impeding the biological viability of the stocks, nor the incentives for crews to remain in the fishery. We also identify reachable fishing mortality targets in the MSY ranges for these two species, given existing technical interactions.
\end{abstract}

Keywords Eco-viability · Mixed fisheries management $\cdot$ Bio-economic modelling $\cdot$ Integrated TAC advice

\section{Introduction}

Ecosystem-based approaches are increasingly being adopted for the management of natural resources, and fisheries make no exception, with the proposal of ecosystem-based fisheries management (EBFM) guidelines in the early 2000s [1, 2], and their subsequent implementation in policy $[3,4]$.

Among other aspirations, EBFM aims at accounting for the technical interactions among jointly caught species

Electronic supplementary material The online version of this article (https://doi.org/10.1007/s10666-019-09685-7) contains supplementary material, which is available to authorised users.

Florence Briton

florence.briton@ifremer.fr

1 Ifremer, Univ Brest, CNRS, UMR 6308, AMURE, Unité d'Economie Maritime, IUEM, 29280, Plouzané, France

2 Ifremer, Unité Sciences et Technologies Halieutiques, Brest, France in mixed fisheries. Joint production in mixed fisheries constrains the ability of fishing operators to fully use the quotas they have been allocated for different species. In a management scheme where individual quotas are not transferable, if harvesters stop fishing once they have reached their most limiting quota, any quota they have left for the other species is lost. The existence of unfished quotas may create an incentive for harvesters to continue fishing in order to fully use their fishing opportunities on valuable species while discarding or illegally selling the catches of their "choke species" [5], i.e. the species for which they do not have quota. In addition to excessive pressure on the stocks of concern, discards of "choke species" can compromise the reliability of catch data underlying stock assessments as they make evaluation of the quantity of fish that is actually removed from the stock more difficult [6]. It is therefore particularly relevant to anticipate any quota underconsumption which may result from joint production. Indeed, minimising such underconsumption is likely to facilitate compliance with quota regulations.

Attempts to account for the multispecies nature of fisheries in scientific catch recommendations have been 
developing in many jurisdictions, usually based on adaptations of the historical, and well-established single-species assessment framework. In Europe, the FCube framework [7, 8] has been used by ICES since 2009 to reconcile singlespecies MSY (maximum sustainable yield) catch recommendations for the North Sea, Celtic Sea and Iberian Waters mixed fisheries. The introduction of a landing obligation as part of the latest reform of the common fisheries policy (CFP) [9] highlighted the potential mismatches between catch opportunities and fishing practices, and their determinant role for the economic viability of a number of European fleets $[10,11]$. A degree of flexibility has been sought with the definition of target ranges around MSY, rather than single target reference points [12] and discussions on how such ranges can be used in practice are ongoing [13]. In Australia, the Commonwealth harvest strategy policy identified maximum economic yield (MEY) as a target for management [14], which has been interpreted in a context of mixed fisheries as maximising the economic returns from the fishery as a whole [15]. This approach has the advantage of explicitly accounting for the technical interactions observed in mixed fisheries. The practical implementation of this approach, however, has proved difficult, as it requires both a good knowledge of all commercial stocks in a mixed fishery (where only the most valuable stocks are generally well known) and a reliable representation of its economic components (i.e. fleets' cost structures and market prices) [15, $16]$.

The move towards EBFM also calls for the formulation of multi-dimensional objectives that integrate the preservation of biological resources as well as the services they provide to society. So far, fisheries management objectives have generally been formulated as the maximisation of a quantity, be it the long-term production of the fishery when setting target reference points at the MSY, ${ }^{1}$ or the sustainable economic returns to the fishing industry when aiming at the MEY. However, such maximising approaches often fall short of embedding multi-criteria objectives as argued by Martinet et al. [17]. In Europe, despite the CFP regulation specifically stating that "the common fisheries policy shall ensure exploitation of living aquatic resources that provides sustainable economic, environmental and social conditions" [18], ICES scientific catch recommendations are only based on the evaluation of the stocks status, with no account nor insight into the economic or social impacts of fishing. Based on the observation that ICES catch advice is often disregarded by EU member states' fisheries ministers $[19,20]$, who are ultimately constrained by the social acceptability of their decisions, ICES has recognised the

\footnotetext{
${ }^{1} \mathrm{MSY}$ is defined as a limit reference point in the USA (MagnusonStevens Act, 2007) and in the European Union (Common Fisheries Policy, 2013).
}

need to provide more integrated management advice [21] in order to increase the transparency of the decision-making process. The work presented in this paper contributes to the ongoing debate among the scientific community on how to incorporate social and economic considerations in their recommendations to decision-makers, with particular emphasis on mixed fisheries total allowable catch (TAC) advice [22, 23].

Viability theory $[24,25]$ is particularly well-suited to account for the variety of sustainability requirements faced by a socio-ecosystem, and has been recognised as a relevant assessment framework to support management of renewable resources (review by [26]). Often referred to as co-viabily or eco-viability when constraints of various types (e.g. biological, economic, social) are to be met simultaneously, the viability approach consists in identifying paths of a system's evolution that remain within predefined acceptability bounds. As opposed to optimisation approaches which require the different objectives to be weighed one against another, the approach gives equal importance to the objectives identified as component parts of the system's sustainability. Indeed, an evolution of the system is considered viable if and only if all viability thresholds are respected at any time. Such an intertemporal requirement also allows to account for inter-generational equity, as highlighted by [2729]. As it does not aim for a particular target but rather looks for a viable operating space, the viability approach seem particularly well-suited to address the flexibility requirements that are strongly needed for the management of mixed fisheries [30].

Since the mathematical formulation of viability theory in the early 1990s, nearly half of its applications have been fisheries study cases [26]. Most study cases investigated how the inputs (e.g fishing effort, fleet size, investment in the fishery) should be set in order to maintain or restore a fishery's viability [17, 31-35]. Considering the fishery's inputs as the control variable in viability studies provides useful advice for the management of fisheries under effort regulation. However, it lacks operationality for fisheries managed under output controls where the regulation exerts on catches via the definition of total allowable catches (TACs) and quotas. This implementation of catch limits on exploited stocks has now become a keystone in the management of many fisheries worldwide (including in the USA, the EU except in the Mediteranean, Australia, New Zealand, Iceland, and South Africa). Hence, it seems crucial to adapt the viability assessment framework to fisheries under output controls (and the associated catch share management systems). Scientific advice in such fisheries is generally given in terms of total catches that can be biologically sustained by the stock, the estimation of which derives from population models when possible, or from the application of some precautionary decision rules. 
Successfully managing a fishery from the output side not only requires setting appropriate caps on total catches (i.e. how much can be fished), but also identifying means of incentivising efficient prosecution of the fishery (i.e who gets which share of the catch), which is widely absent from current ichtyocentric scientific advice. Thinking about by whom and how a quota is fished is far from anecdotal as this can impact (1) the stock status, as all gears are not equally selective; (2) the economic performance of the fishery, as all harvesters are not equally efficient; and (3) how the economic and social benefits (direct and indirect employment, supply of fish, persistence of local knowledge and tradition) generated by the exploitation of a common resource will be redistributed [36].

In the last two decades, the development of integrated ecological-economic fisheries models (IEEFMs) has opened the way to a better understanding of the feedbacks between ecological and socio-economic dynamics, and the formulation of management advice embedding both biological and socio-economic assessments [37]. The development of these models also enabled fishing behaviour to be explicitly modelled. Consequently, fishing effort and its direct effect on the resource (i.e. the fishing mortality) emerge as the response of harvesters to an ensemble of regulations and/or other incentives rather than being treated exogenously. Since fisheries management is about seeking to manage fishing activities, not resources [38, 39], representation of fishers behaviour in the models provides better insights regarding the expected effectiveness of management options in meeting specified objectives. Our work follows in this vein by explicitly modelling the options fishers face, given catch limits on the different species they catch.

The objective of the present paper is to develop an approach to management advice that integrates multiple objectives for mixed fisheries under output controls. After describing the IEEFM used to simulate management scenarios, we define the eco-viability framework used to reconcile biological and economic management objectives. We apply the approach to the Bay of Biscay demersal mixed fishery, for which we present a first attempt at providing integrated TAC advice, accounting for multiple objectives. We show that gains can be expected in terms of longterm economic viability of the fleets without impeding the biological viability of the stocks, nor the incentives for crews to remain in the fishery.

\section{The Bay of Biscay Mixed Demersal Fishery}

The Bay of Biscay has historically been an important fishing region in the North-East Atlantic, especially for France. More than 200 species are fished in the Bay but $80 \%$ of landings in value were accounted for by 21 species in 2016. The most valuable species are bentho-demersal species, namely Norway lobster, anglerfish, common sole, European hake and European seabass. In 2016, the landings of those 5 species from the Bay generated a gross value of $200 \mathrm{M€}$.

Fisheries in the Bay of Biscay are managed under the CFP, with some managed by coastal states. Management mostly relies on conservation measures (TACs, minimum landing sizes), and about $1 / 4$ of the stocks are managed through EU TAC. Multi-annual plans are also in place for common sole (Council Regulation (EC) No 388/2006) and Northern hake (Council Regulation (EC) No 388/2006), but should be both replaced by the multiannual plan for the Western Waters [40], a single regulation embracing demersal and deep-sea stocks, and their fisheries in the Western Waters. TACs are set in line with the MSY objective stated in the CFP. France is allocated a share of the EU TACs following the "relative stability" principle and allocates its national quotas to producer organisations (POs) proportionally to their members' historical catches. POs are responsible for managing their quotas and specifically making sure they are not overcaught [41]. Individual harvesters do not own the fishing rights but are limited to fishing what they have been allocated by the PO, which strongly contrasts with fisheries managed with individual (eventually tradable) catch shares.

The Bay of Biscay bentho-demersal fishery is a typical mixed fishery where many fleets operate in multiple fisheries, either sequentially because of fishing seasonality or simultaneously because of non-selective fishing practices. As shown on Fig. 1, some fleets are specialised in targeting particular species which account for most of their revenue (e.g. hake longliners, hake gillnetters, bass longliners and specialised Norway lobster trawlers), whereas others depend on a broader range of species (e.g. mixed netters, sole gillnetters and trawlers). The technical interactions are not accounted for in TAC decisions made at the European level, which can cause discrepancies between fishing opportunities and what is technically achievable for the fleets. In 2016, French quotas for common sole, Norway lobster, whiting and megrim have been fully caught. Those for Pollock, anglerfish and blue whiting were respectively taken up by $87 \%, 85 \%$ and $72 \%$, whereas there was less tension on the hake quota $(60 \%$ uptake). So far, discards in the fishery have been more related to bycatch of undersized individuals (e.g. small hakes in the Norway lobster fishery) and quality rather than to major choke effects.

Besides ensuring a sustainable exploitation of fish stocks, interviews with representatives from POs highlighted that an ageing fishing fleet and the volatility of crews are 
Fig. 1 Economic dependence of the demersal fleets on the 5 key bentho-demersal species.

Economic dependence was calculated as the share of each species in the gross value of landings of the fleet. Codes on the left vertical axis correspond to segments of vessels of different lengths for each fleet. Source: [42]

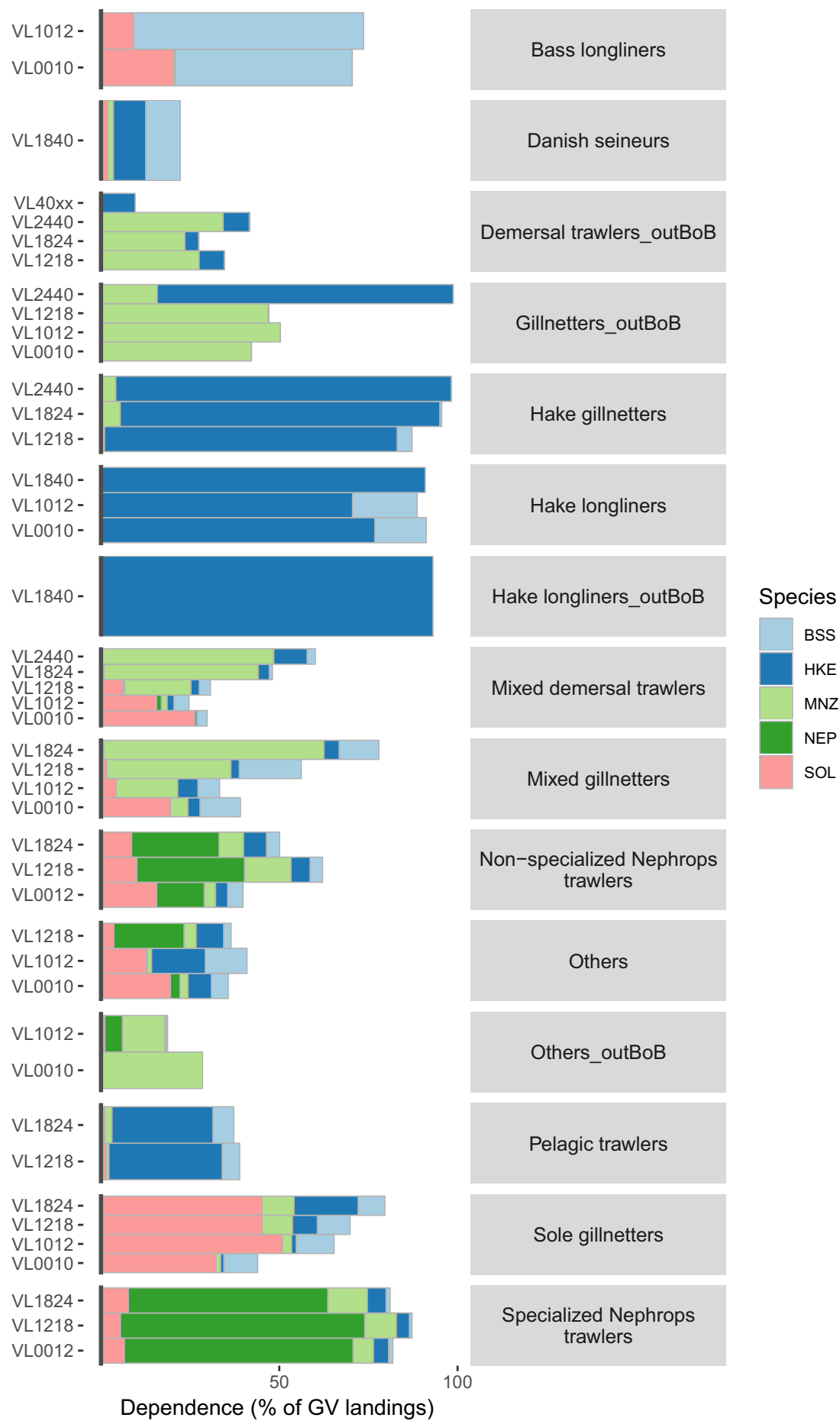

major concerns in the region. Issues of overcapacity in the region have also been highlighted in the past [34, 43, 44] and addressed through limited entry and publicly funded decommissioning schemes [45]. Although we estimated that in 2016 all 44 fishing segments in the fishery had overall positive gross profits, only 41 showed positive net profits, which highlights the difficulties in renewing the fishing fleet. The economic performance of some segments (e.g. trawlers) is also highly sensitive to the variability in fuel price. Crew volatility is likely to be the reason for wages above the national average as our estimations show that all fishing segments were in average paying their crews a fulltime equivalent wage above the mean wage of a French seaman. 


\section{Bio-economic Model}

Simulations were run with the bio-economic model IAM referenced in [37] and [46], and already used to assess the impacts of various management scenarios on the Bay of Biscay mixed fishery [43, 44, 47]. IAM is a multispecies, multi-fleet or multi-vessel, and multi-metier model that can include stochasticity on recruitment and fish prices. It runs with an annual time step and is spatially aggregated. In line with the management strategy evaluation (MSE) approach [48], IAM was divided into an operating model which represents the biological and harvesting components of the system and a management procedure module which implements management regulations.

\subsection{Operating Model}

\subsubsection{Biological Module}

Depending on data availability and/or its importance in the modelled system, a stock can either be modelled using annual age-based dynamics, quarterly age-based dynamics, or a static model which assumes that the total biomass of the stock remains constant.

Age-based dynamics are governed by the following:

$$
\begin{aligned}
& N_{s, a+1, t+1}=N_{s, a, t} e^{-Z_{s, a, t}} \quad a \in\left[A_{\min } ; A_{\max }-1\right], \\
& N_{s, A_{\max }, t+1}=N_{s, A_{\max }-1, t} e^{-Z_{s, A_{\max }-1, t}}+N_{s, A_{\max }, t} e^{-Z_{s, A_{\max , t}},}
\end{aligned}
$$

where $N_{s, a, t}$ stands for the number of individuals of age $a$ from stock $s$ at time $t$, which experience a total mortality $Z_{s, a, t}$ equal to the sum of natural mortality $M_{s, a}$ and fishing mortality $F_{s, a, t}$. The fishing mortality applied to the stock is the sum of the fishing mortalities by vessel $i$ and metier $m\left(F_{s, a, i, m, t}\right)$ and the fishing mortality exerted by non-explicitly modelled fleets $\left(F_{s, a, t, \text { OTH }}\right): F_{s, a, t}=$ $\sum_{i, m} F_{s, a, i, m, t}+F_{s, a, t, \mathrm{OTH}}$.

The quarterly version of this age-based dynamics is detailed in Supplementary Material - Table S.6(a).

Fishing mortalities at age by vessel and metier are proportional to individual fishing efforts by metier, assuming a constant catchability rate as follows:

$F_{i, m, s, a, t}=q_{i, m, s, a} \times E_{i, m, t}$.

The spawning stock biomass (SSB) is calculated as follows:

$\mathrm{SSB}_{s, t}=\sum_{a} \operatorname{Mat}_{s, a} w_{s, a} N_{s, a, t}$,

with $\mathrm{Mat}_{s, a}$ being the proportion of mature individuals of age $a$ in stock $s$ and $w_{s, a}$ the stock's mean weights at age.

\subsubsection{Short-term Fishing Behaviour Module}

The short-term behaviour module determines fishing efforts at the metier level for each individual harvester. A metier is a combination of gear and targeted species, and aims at accounting for regional fishing specialisations. Individual fishing efforts at the metier level $\left(E_{i, m, t}\right)$ ensuing from the quota constraint are calculated in a 2 -step process:

1. Calculation of the effort $E_{i, m, s, t}$ required to catch the quota $Q_{i, s, t}$ for each individual harvester $i$, metier $m$ and stock $s$. Assuming a constant allocation of the individual total effort $E_{i, t}$ among the different metiers used by harvester $i$, the problem to solve can be formulated as follows:

Find $\lambda_{i, s, t}$ such that $\left\{\begin{aligned} \sum_{m} L_{i, m, s, t} & =Q_{i, s, t}, \\ E_{i, m, s, t} & =E_{i, s, t} \times \alpha_{i, m}, \\ E_{i, s, t} & =E_{i, t_{0}} \times \lambda_{i, s, t} .\end{aligned}\right.$

Individual landings by metier for the species for which the dynamics are explicitly modelled (hereafter referred to as "dynamic species") are given by the following:

$L_{i, m, s, a, t}=\left(1-d_{s, a}\right) w_{s, a} \frac{F_{i, m, s, a, t}}{Z_{s, a, t}} N_{s, a, t}\left(1-e^{-Z_{s, a, t}}\right)$,

with $d_{s, a}$ standing for the proportion of discarded individuals of age $a$ and stock $s$ (assumed constant), and $w_{s, a}$ being the individual weight at age in the landings of stock $s$.

Those for static species are given by the following:

$L_{i, m, s, a, t}=\mathrm{LPUE}_{i, m, s} \times E_{i, m, t}$,

LPUE $_{i, m, s}$ being the landings of stock $s$ per unit of effort for individual harvester $i$ using metier $m$.

$\alpha_{i, m}$ is the proportion of total effort of individual $i$ attributed to metier $m$. For the sake of simplicity, we assume that individual harvesters practice the different metiers in the same proportions as they did in the reference year, that is $\alpha_{i, m}=\alpha_{i, m, t_{0}}$. This assumption is justified as tradition was shown to be an important driver of fishing practices in other demersal fisheries $[49,50]$. Fishermen's adaptation to seasonal dynamics of exploited stocks, weather conditions and seasonal gear restrictions count among likely explanations of the strong inertia often observed in fishing patterns. Introducing flexibility in the allocation of effort across metiers at the individual fisher level was beyond the scope of the present study, but will be the focus of further research using the model. Through the Baranov catch (5), individual landings are a function of the total mortality rate exerted on the stock, itself depending 
on the fishing mortality exerted by each harvester. Problem 4 was therefore solved through a convergent iterative process inspired by the method of the Lagrange multiplier.

2. Effort reconciliation at the metier level so that each fisherman stops fishing with metier $m$ either when its most constraining quota is exhausted or when he has reached the upper limit $E_{\max }$, i.e.:

$E_{i, m, t}=\min \left(E_{\max } \times \alpha_{i, m}, \min _{s} E_{i, m, s, t}\right)$.

\subsubsection{Economic Module}

This module calculates for each individual harvester $i$ a variety of economic outputs described in [44].

Among them, three indicators are of particular interest:

- The gross operating surplus (GOS), i.e. the gross income from landings minus all operating costs:

$$
\begin{aligned}
& \operatorname{GOS}_{i, t}=\left(1-\operatorname{cshr}_{i}\right) \times \operatorname{rtbs}_{i, t}-\mathrm{Cfix}_{i}, \\
& \text { with } \operatorname{rtbs}_{i, t}=\mathrm{GVL}_{i, t}-\sum_{m} \operatorname{CvarUE}_{i, m} \times E_{i, m, t},
\end{aligned}
$$

rtbs being the "return to be shared" and cshr its proportion allocated to the crew, GVL the gross value of landings, CvarUE the variable costs per unit effort and Cfix the fixed costs.

- The net operating surplus (NOS), i.e. the gross operating surplus minus capital depreciation costs Cdep

$\operatorname{NOS}_{i, t}=\operatorname{GOS}_{i, t}-\mathrm{Cdep}_{i}$.

- The full-time equivalent (FTE) wage of the crew ( wage $_{\mathrm{FTE}}$ ):

wage $_{\mathrm{FTE}_{i, t}}=\frac{\operatorname{cshr}_{i} \times \mathrm{rtbs}_{i, t}}{\mathrm{FTE}_{i, t}}$,

FTE being the full-time equivalent number of men on board a vessel.

\subsection{Management procedures}

The management procedure module is used to set and allocate TACs. At the end of each year, the EU TAC for the following year is calculated so that the stock is harvested under a fishing mortality $\bar{F}_{\text {target }}$ according to the procedure described in Supplementary Material S.3.1. Hereafter, the term management strategy will refer to the specification of fishing mortality targets (and associated catch limitations) for the regulated stocks.

The French quota $Q_{s, t}$ is derived from the EU TAC according to the relative stability principle:

$Q_{s, t}=\mathrm{TACshr}_{s} \times \mathrm{TAC}_{s, t}$,

with TACshr $r_{s}$ the French share of the EU TAC of stock $s$.
The national quota is then allocated to producer organisations (POs), and in turn to individual harvesters following an allocation key $\mathrm{Qshr}_{s}$ provided as an input: ${ }^{2}$

$Q_{i, s, t}=Q s h r_{i, s} \times Q_{s, t}$.

\section{Eco-viability Evaluation}

\subsection{Eco-viability Framework}

Identifying appropriate acceptability constraints is a determinant step in the operationalization of the viability approach. It consists in the following:

1. Identifying the elements which determine the persistence of the system, i.e which variables are constrained.

2. Defining the acceptability threshold for the identified variables.

3. Identifying tolerance levels regarding the frequency with which these thresholds should be met in stochastic systems [51].

For this study, we conditioned the viability of the fishing activity on the maintenance of its production factors. First, as any activity based on the exploitation of a natural resource, fishing can only persist if the resource, here the fish stocks, is present. In this regard, the spawning biomass of the stocks should not fall below a limit threshold $B_{\text {lim }}$, under which recruitment is likely to be impaired [52].

The viability of stock $s$ was thus calculated as follows:

$$
\begin{aligned}
V_{\mathrm{BIO}}(s) & =1 & & \text { if } \quad \operatorname{SSB}_{s}(t) \geq B_{\lim _{s}} \quad \forall t \in\left[t_{0} ; t_{f}\right], \\
& =0 & & \text { otherwise. }
\end{aligned}
$$

We also calculated a biological viability index aggregated across all dynamically modelled stocks:

$$
\begin{aligned}
V_{\mathrm{BIO}}(\mathrm{ALL})= & 1 \quad \text { if } \quad \operatorname{SSB}_{s}(t) \geq B_{\lim _{s}} \forall t \in\left[t_{0} ; t_{f}\right], \\
& \forall s \in\{\mathrm{HKE}, \mathrm{SOL}, \mathrm{BSS}, \mathrm{NEP}\}, \\
= & 0 \quad \text { otherwise. }
\end{aligned}
$$

Second, we consider the fact that fishing companies should be able to maintain their means of production, i.e. capital and labour. Ensuring the renewal of the physical capital for fishing (i.e. vessel, gears and motor) was expressed as a need to maintain positive NOS. In other words, fishing companies should be able to make sufficient profits not only to cover operating costs (fuels costs, fixed costs and crew costs) but also to cover the depreciation of their capital, in order to be able to renew their equipments when needed. This can be seen as a long-term economic viability constraint, which was not applied on a yearly

\footnotetext{
${ }^{2}$ We here assume that observed individual allocations of catch shares result from the management operated by POs.
} 
basis but rather evaluated over the 10-year simulation period $\left(\overline{\mathrm{NOS}}=\frac{\sum_{t^{\prime}=t_{0}}^{t_{f}} \mathrm{GOS}\left(t^{\prime}\right)}{10}\right)$, deemed a relevant time scale for capital renewal.

The long-term viability of fleet $f$ was thus calculated as follows:

$$
\begin{aligned}
& V_{\mathrm{LT}}(f)=1 \quad \text { if } \quad \overline{\operatorname{NOS}}(f) \geq 0, \\
& =0 \quad \text { otherwise. }
\end{aligned}
$$

In addition to the long-term economic viability of the fleets, we also considered their capacity to regularly cover their operating costs throughout the simulation period, i.e. to show a positive gross operating surplus. Individual economic data [53] showed that having negative gross profits in 1 year did not necessarily prevent fishing vessels from continued operation in the fishery in the following years. This profitability constraint was thus applied on the GOS averaged over a 2-year period $(\overline{\mathrm{GOS}}(t)=$ $\left.\frac{\sum_{t^{\prime}=t-1}^{t} \operatorname{GOS}\left(t^{\prime}\right)}{2}\right)$. This short-term economic objective is less constraining than the long-term objective defined supra since it does not account for capital depreciation costs. However, it evaluates the regularity of economic performance, which is considered important by the fishing industry.

The short-term viability of fleet $f$ was calculated as follows:

$$
\begin{array}{rlrl}
V_{\mathrm{ST}}(f) & =1 \quad \text { if } \quad \overline{\mathrm{GOS}}(f, t) \geq 0 \quad \forall t \in\left[t_{0}+1 ; t_{f}\right], \\
& =0 & & \text { otherwise. }
\end{array}
$$

Third, a key production factor to maintain in the fishery is the workforce, especially as interviews with representatives from French producer organisations highlighted the extreme volatility of crews in the region. Keeping fishing crews active in the fishery was ensured in this application by maintaining their annual full-time equivalent wage above a minimim threshold wage $\mathrm{FTE}_{\text {min }}$.

The crew viability of fleet $f$ was calculated as follows:

$$
\begin{aligned}
V_{\mathrm{CREW}}(f) & =1 \quad \text { if } \operatorname{wage}_{\mathrm{FTE}}(f, t) \\
& \geq \text { wage }_{\mathrm{FTE}_{\text {min }}} \forall t \in\left[t_{0} ; t_{f}\right],=0 \quad \text { otherwise. }
\end{aligned}
$$

\subsection{Eco-viability Under Uncertainty}

Precautionary management requires articulating the acceptability constraints with possible uncertainties on the modelled processes. In our model, stochasticity applies to the recruitment of the dynamic species. De Lara Doyen [54] and De Lara et al. [29] presented how uncertainties could be addressed in the viability framework, thanks to the concept of stochastic viability which is interpreted as maximising the probability of respecting acceptability constraints. We estimated this probability through a Monte Carlo simulation approach, which consists in running a number $n_{\text {rep }}$ of replicates for which the value of the uncertain factor(s) is drawn in a probability distribution.

For each management strategy St, probabilities were derived for each type of viability: $P_{V_{\mathrm{BIO}}}(\mathrm{St}, s), P_{V_{\mathrm{ST}}}(\mathrm{St}, f)$, $P_{V_{\mathrm{LT}}}(\mathrm{St}, f)$ and $P_{V_{\mathrm{CREW}}}(S t, f)$. As viability indicators defined in Section 4.1 are booleans, the probability of viability was calculated as the sum of the viability indicator over all replicates rep divided by the number of replicates $n_{\text {rep }}$ as follows :

$$
P_{V}(S t)=\frac{\sum_{\mathrm{rep}=1}^{n_{\text {rep }}} V(\mathrm{St}, \mathrm{rep})}{n_{\mathrm{rep}}} .
$$

Examples of stochastic economic trajectories and the associated viability probabilities are given in Supplementary Material - Figure S.1.

\section{Model's Dimensions and Calibration}

To select the fleets to model, we considered the four key demersal stocks under EU TAC management in the Bay of Biscay (Northern stock of European hake, Bay of Biscay stock of common sole, Bay of Biscay stock of Norway lobster, and anglerfish in the Bay of Biscay and Celtic Sea). Modelled vessels were the French vessels contributing significantly to the landings of at least one of the 4 key stocks (in order to ensure that $>95 \%$ of the landings of each stock was accounted for by the model). In addition, we identified fleets depending economically on a stock as those for which more than $30 \%$ of the gross value of landings was made up of landings of this stock. Vessels that were economically dependent on one of the stocks were also included in the model, even if their contribution to landings was limited. In total, 710 vessels were identified and allocated to fleets adapted from the European Data Collection Framework typology of fishing fleets [55], to account for regional specificities. The fleets were further divided into length categories to define segments sharing the same cost structures. Each vessel was modelled individually, but results were aggregated at the segment level by averaging economic indicators across all vessels in the segment, in order to represent regional differences in the structure of fishing activities from North to South of the Bay. Fishing activity of the vessels was described through 13 metiers referenced in Appendix Table 4.

The 21 most important species or group of species (e.g. anglerfish or megrim) caught by the modelled fleets in the Bay of Biscay were explicitly represented in the model (list in Appendix - Table 3), and all remaining catches were pooled in an "Other species" category. As mentioned 

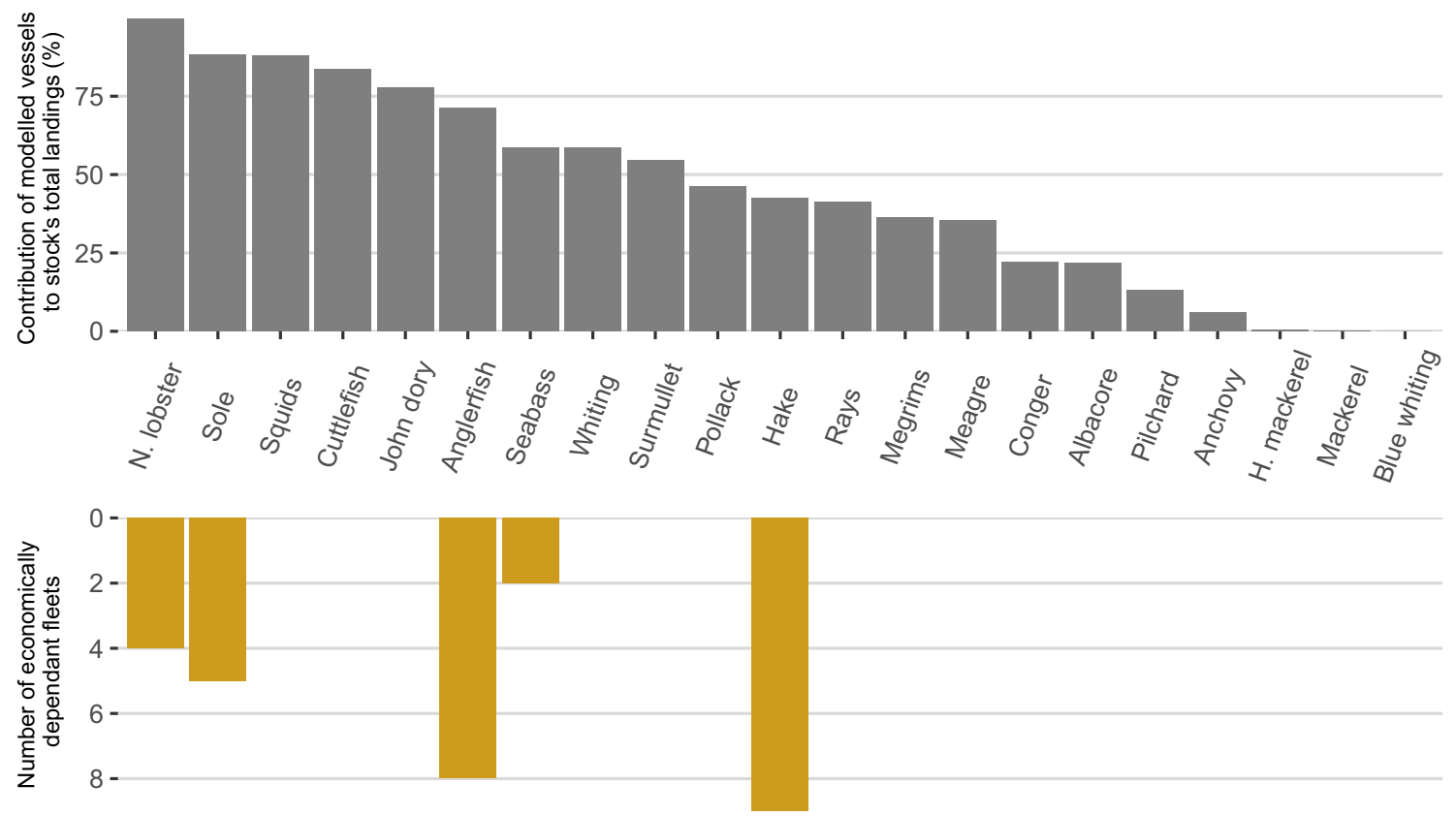

Fig. 2 Contribution of the modelled vessels to the total landings of the stocks (top panel) and number of fleets economically dependent on the important commercial species in the Bay of Biscay (lower panel). A fleet was considered economically dependent on a stock when the

in Section 3, some species were modelled dynamically, whereas others were considered "static". The possibility to dynamically model a stock is first constrained by data availability: for many stocks, data is too scarce to assess the stock with an analytical model. In the European context, this concerns all stocks which are considered to be data limited (ICES categories 3 to $6^{3}$ ) (cf Appendix - Table 3). The rationale for the selection of stocks that were modelled dynamically was as follows:

- The modelled vessels should be important contributors to the total landings of the stock, since any change in the fishing effort of those vessels is likely to impact the stock status. On the contrary, all other things (effort of other fleets, environmental conditions) being equal, it is reasonable to assume a constant biomass of the stocks that are only marginally impacted by the effort of the modelled fleets.

- At least one fleet was economically dependent on the stock. The economic viability of such fleets is likely to be impacted by changes in catch rates (i.e. catches per unit of effort) consecutive to changes in stock biomass.

Only 5 species met those criteria as shown by Fig. 2, namely Norway lobster, common sole, anglerfish, European

\footnotetext{
${ }^{3}$ On the basis of available knowledge, ICES classifies the stocks into six main categories. Stocks in categories 1 and 2 are qualified as "data-rich", whereas others fall into the "data-limited" category.
}

landings of the latter accounted for $>30 \%$ of the fleet's total value of landings. The absence of bar on the lower panel means that no fleet was economically dependent on the stock. Sources: French landings and value of landings: [42]; total landings of the stocks: [56]

seabass and European hake. Among those, only Norway lobster, common sole, European seabass and European hake could be dynamically modelled in IAM as the species of anglerfish were classified as data-limited.

Parameters for the stock dynamics of Northern hake, common sole and European seabass were derived from the 2016 ICES stock assessments [57]. For Norway lobster, they were estimated from an XSA $[58,59]$ stock assessment. The recent UWTV survey "LANGOLF-TV", which started in 2014, was included as an additional tunning fleet compared to XSA stock assessments carried out before 2016 (see [57] for more details on the survey). All parameters are given in Supplementary Material - Table S.1. Annual recruitments for those stocks were estimated from Hockey-Stick stockrecruitment relationships. Uncertainties on recruitement were accounted for by randomly sampling the parameters of the stock-recruitment relationship among a list of potential candidates estimated by softwares PlotMSY (sole) or EqSim (hake and seabass) as detailed in [60].

Effort and production data by vessel and metier were calculated from the SACROIS database which is an algorithm crossing multiple existing data sources (auction halls, logbooks, dealer reports) to provide the best possible estimation of effort and production by vessel at the trip level [42]. The maximal fishing effort $E_{\max }$ was set uniformly for all vessels at 300 days/year. Fish prices were kept constant and equal to the ones recorded in auction sales in 2016 [42]. Prices were defined at the vessel and metier level in order 
to account for spatial variations in prices and differences in prices between gears (e.g. seabass fished with a long line is more expensive than fished with a net or a trawl).

Cost structures were estimated for each fleet segment from 2016 economic data [53]. The vessels' cost structures were derived from those estimated for their segment, following the procedure described in Supplementary Material S.2.2.

$\mathrm{TACshr}_{s}$ was set as the proportion of French landings relative to total landings in 2016. French landings were provided by [42], and total landings by [56].

Acceptability constraints and the value of the thresholds for this application are summarised in Table 1.

\section{Management Strategies}

In order for the results to be displayed in two dimensions, we restricted our analysis to the joint management of two species, chosen for their historic importance in the Bay of Biscay demersal fishery, namely Northern hake and common sole. We recognise that it is a simplification of current management in the Bay of Biscay since many other stocks are actually under TAC regulation in the region. However, this stylised application has been beneficial both in terms of development and presentation of the approach as outputs were easily tractable and conveyable, and trade-offs between different objectives being made transparent.

In the remainder of the paper, a management strategy St will refer to a couple of target fishing mortalities $F_{\text {targ }}$ for the 2 stocks under TAC management in the model, namely hake and sole, associated with TAC recommendations. Let $F_{\text {targ }}$ be an element of $I_{\mathrm{SOL}}$ and $F_{\mathrm{targ}}$ bKE $I_{\mathrm{HKE}}$, then St is an element of $I_{\mathrm{SOL}} \times I_{\mathrm{HKE}}$. For simulation purposes, this 2D space was discretised in a grid of $20 \times$ 20 which amounts to 400 simulated strategies. Based on preliminary analyses, the results presented here correspond to $I_{\mathrm{SOL}}=I_{\mathrm{HKE}}=[0.1 ; 0.8]$.

Additional strategies corresponding to status quo targets (i.e. $\left(F_{\mathrm{targ}_{\mathrm{SOL}}} ; F_{\mathrm{targ}_{\mathrm{HKE}}}\right)=\left(F_{\mathrm{SOL}_{2016}} ; F_{\mathrm{HKE}_{2016}}\right)=$ $(0.42 ; 0.27))$ and single-species $F_{\mathrm{MSY}}$ reference points $\left(F_{\mathrm{MSY}_{\mathrm{SOL}}}=0.33\right.$ and $\left.F_{\mathrm{MSY}} \mathrm{HKE}=0.28,[65]\right)$ were also simulated. Simulated $F_{\text {targ }}$ strategies were also compared to the stocks' MSY ranges defined by [65] as the fishing mortality ranges resulting in long-term yield no less than $95 \%$ of MSY.

Strategies maximising economic yield of the hake and sole fishery were identified among the simulated strategies. Dynamic maximum economic yield (MEY) refers to the maximisation of the fishery's net present value calculated as follows:

$\mathrm{NPV}=\frac{1}{\sum_{t}(1+\delta)^{t-t_{0}}} \sum_{i, s \in(\mathrm{SOL} ; \mathrm{HKE})} \mathrm{GVL}_{i, s, t}-C_{i, s, t}$,

with $\delta$ being the discount factor, and $C_{i, s, t}$ the costs of individual $i$ at time $t$ associated to the harvest of species $s$, which were estimated as a fraction of total $\operatorname{costs} C_{i, t}=$ $C_{\mathrm{var}_{i, t}}+C_{\mathrm{crew}_{i, t}}+C_{\mathrm{fix}_{i, t}}+C_{\mathrm{dep}_{i, t}}$ equal to the share of species $s$ in the gross value of landings of individual $i$ :

$C_{i, s, t}=\frac{\mathrm{GVL}_{i, s, t}}{\mathrm{GVL}_{i, t}} \times C_{i, t}$.

Dynamic MEY was identified for discount factors of 0 and 5\%. A static MEY was also calculated as the maximal value of the fishery's net profit at the end of the simulation period.

Strategies ensuring that the TAC of the two species can be simultaneously caught given the joint production formed what we called the operating domain of the fishery.

Each strategy was simulated over a 10 -year period, and in order to account for uncertainties on the recruitment of

Table 1 Acceptability constraints

\begin{tabular}{|c|c|c|c|c|c|c|}
\hline Aim & Name & Signification & Aggreg. level & Time scale & Value & Source \\
\hline Stock persistence & $\begin{array}{l}B_{\lim _{\mathrm{SOL}}} \\
B_{\lim _{\mathrm{HKE}}} \\
B_{\lim _{\mathrm{BSS}}} \\
B_{\lim _{\mathrm{NEP}}}\end{array}$ & Limit biomass reference point & Stock & Year & $\begin{array}{l}7,600 \mathrm{t} \\
32,000 \mathrm{t} \\
11,920 \mathrm{t} \\
5,557 \mathrm{t}\end{array}$ & $\begin{array}{l}{[61]} \\
{[62]} \\
{[63]} \\
\text { lowest SSB } \\
\text { since 1987 from } \\
\text { XSA (pers.com } \\
\text { S.Fifas) }\end{array}$ \\
\hline Cover operating costs & $\mathrm{GOS}_{\min }$ & Minimal gross operating surplus & fleet & 2-year period & $0 €$ & {$[64]$} \\
\hline Capital renewal & $\mathrm{NOS}_{\text {min }}$ & Minimal net operating surplus & fleet & 10-year period & $0 €$ & {$[64]$} \\
\hline Maintenance of crew & Wage $_{\text {min }}$ & Mean wage of a seaman & fleet & year & $25,246 €$ & $\begin{array}{l}\text { INSEE (cat } \\
692 a \text { ) actualised } \\
\text { data from } 2013 \\
\text { for } 2016\end{array}$ \\
\hline
\end{tabular}




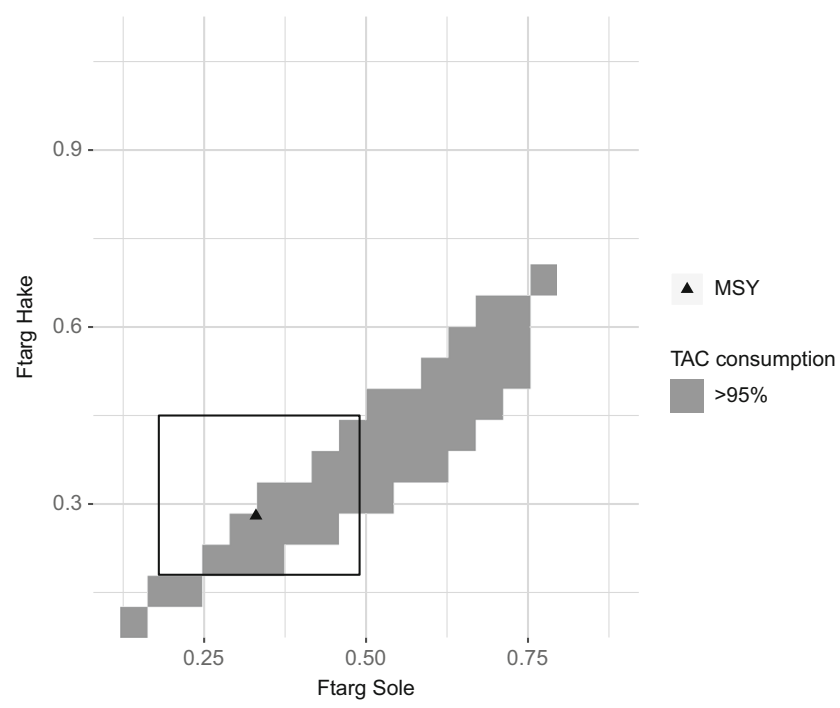

Fig. 3 Operating domain of the fishery defined as the domain where at least $95 \%$ of the quota for both species can be simultaneously caught given joint production contraints. The triangle shows the $F_{\mathrm{MSY}}$ reference points of the 2 species and the black rectangle their $F_{\mathrm{MSY}}$ ranges. Source: IAM model

dynamically modelled stocks, 200 replicates were run for each strategy. 4

\section{Results}

\subsection{The Joint Production Problem}

Figure 3 displays in grey the operating domain of the hake and sole fishery in the Bay of Biscay. If production of hake and sole for the modelled vessels was completely joint, i.e. every harvester fishing hake with one unit of effort of a given metier would also fish sole with the same unit of effort of this metier and vice versa, then the operating space would reduce to a line. In our model representation of the Bay of Biscay demersal fishery, it is not exactly a line, but is closer to a segment: the modelled vessels are not able to fully consume their quotas if the TACs are based on target fishing mortality rates greater than 0.77 for sole and 0.68 for hake. At this point, the vessels are not constrained by the quotas but by the maximal effort limit $E_{\text {max }}$ (which truncates the theoretical perfect joint production line into a segment). The operating space is not strictly uni-dimensionnal: some latitude around the perfect joint production line exists. This room for manoeuvre is due to the fact that production of the two species is not perfectly joint: some vessels do catch both species jointly, whereas others either only fish one species

\footnotetext{
${ }^{4}$ Increasing the number of replicates from 100 to 200 did not impact the results at the scale at which we present them.
}

or do not fish both using the same metier. In the latter case, fishing operators are able to target both species separately and fully use their quotas on both species.

As shown on Fig. 3, the single-species $F_{\mathrm{MSY}}$ reference points fall within the operating domain, which means that they are achievable targets given the joint production observed in the fishery. Figure 3 also shows that MSY ranges intersect with the operating domain, although they also include combinations that are unreachable.

\subsection{Biological Viability}

We then proceed to the identification of biologically viable strategies. As shown on Fig. 4, Norway lobster is the most vulnerable species among the 4 dynamically modelled stocks. Ensuring that its spawning biomass does not fall below $B_{\text {lim }}$ with a probability of $95 \%$ restrains the operating domain presented in Fig. 3 to the dark green domain on Fig. 4, which corresponds to target fishing mortality rates below 0.6 for sole and 0.47 for hake.

\subsection{Fleets' Viability}

The economic viability of the biologically viable operating domain (i.e. the dark green domain in Fig. 4) was then evaluated. For each segment, we calculated its probability to meet the 3 viability constraints described in Section 4.1. A segment was considered viable in a given strategy if its probability of viability was greater than $80 \%$. Figure 5 shows the number of viable segments for each strategy with respect to the three constraints. The number of segments able to maintain positive gross or net profits over the simulation period, increases with fishing mortality targets. In 2016, all 44 segments had a positive GOS, which means that setting fishing mortality targets lower than 0.31 for sole and 0.26 for hake will jeopardise the short-term viability of initially viable segments. Regarding long-term viability, 41 segments showed a positive NOS in 2016. Thus, setting fishing mortality targets higher than 0.39 for sole and 0.31 for hake will enable more segments to meet long-term viability objectives than in 2016 .

The ability to maintain crews in the fishery shows a somewhat different evolution. The number of segments able to maintain their crews first increases with fishing mortality targets, until all segments are able to provide a sufficient FTE wage to their crews. Then, as fishing mortality targets increase above 0.52 for sole and 0.31 for hake, the decrease in labour productivity (i.e. the crew share per fishing hour) leaves some segments unable to guarantee the minimum FTE wage to their crews.

Interestingly, harvesting both stocks within their MSY ranges is relatively compatible with short-term economic viability and crew maintenance objectives since both criteria 
Fig. 4 Probability of biological viability of the operating domain by stock and aggregated for all stocks. Source: IAM model
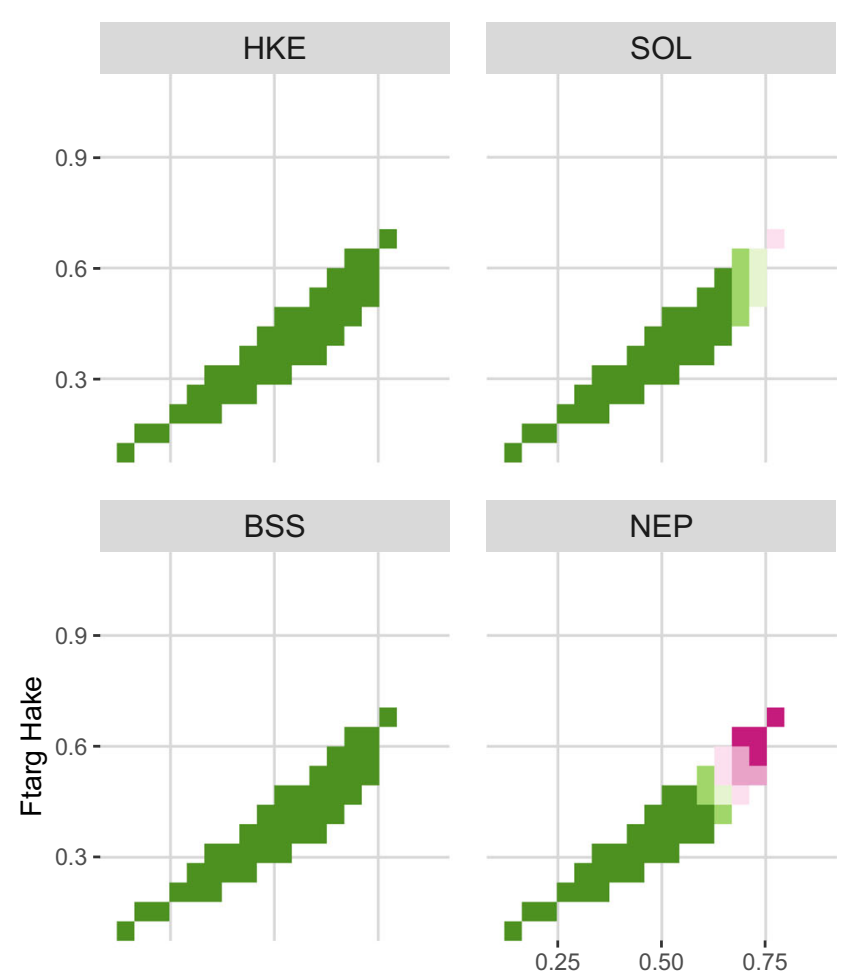

Probability of biological viability

$[0,0.2]$

$(0.2,0.4]$

$(0.4,0.6]$

$(0.6,0.8]$

$(0.8,0.9]$

$(0.95,1]$

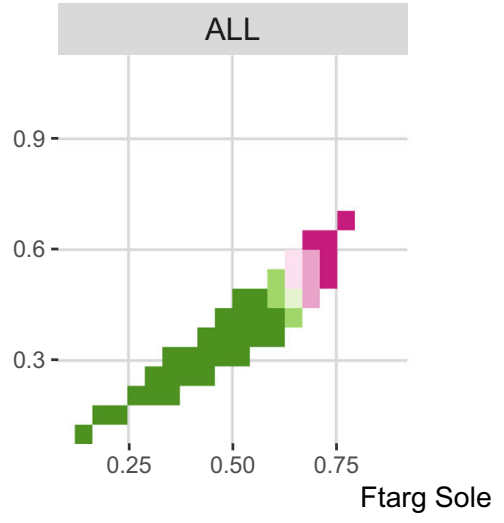

are always met by more than 41 segments within those ranges. However, targeting the lower end of the operating MSY ranges $\left(F_{\operatorname{targ}_{\mathrm{SOL}}}=0.27\right.$ and $\left.F_{\text {targ }_{\mathrm{HKE}}}=0.21\right)$ will prevent 17 segments from meeting long-term economic objectives, whereas fishing at its upper end $\left(F_{\text {targ }}\right.$ soL $=0.48$ and $F_{\text {targ }_{\mathrm{HKE}}}=0.42$ ) allows 43 segments to reach long-term economic viability.

In no strategy can the 3 sustainability criteria be met simultaneously for all segments. However, with fishing mortality targets between 0.48 and 0.52 for sole and of 0.31 for hake (dashed lined rectangle in Fig. 5), all segments meet the short-term viability and crew wage constraints, and 42 over 44 segments generate sufficient profits to ensure the renewal of their capital. Targeting fishing mortality rates in those ranges therefore ensures that the fleets' viability at least improves compared to 2016. This domain of fishing mortality targets will be further referred to as the eco-viable space.

In Fig. 5, strategies that maximise the economic yield of the hake and sole fishery are also identified. Maximising the net present value of the fishery over a 10 -year period leads to high harvest rates on both species $\left(F_{\operatorname{targ}}{ }_{\text {SOL }}=0.73\right.$ and $F_{\text {targ }}=0.48$ for $\delta=5 \%$, and $F_{\text {targ }}=0.65$ and $F_{\operatorname{targ}}=0.36$ for $\delta=0$ ), which fall out of the biologically viable domain. This suggests the prevalence of short-term over long-term profits since the fishery's profits at the end of the simulation period are maximised under much lower harvest rates $\left(F_{\operatorname{targ}_{\mathrm{SOL}}}=0.44\right.$ and $F_{\operatorname{targ}_{\mathrm{HKE}}}=$ 0.26 ). In other words, within a 10 -year time frame, it is more profitable to highly fish now than to reduce fishing to increase tomorrow's profits. It is worth noting that the fishing mortality target which maximises the fishery's net 


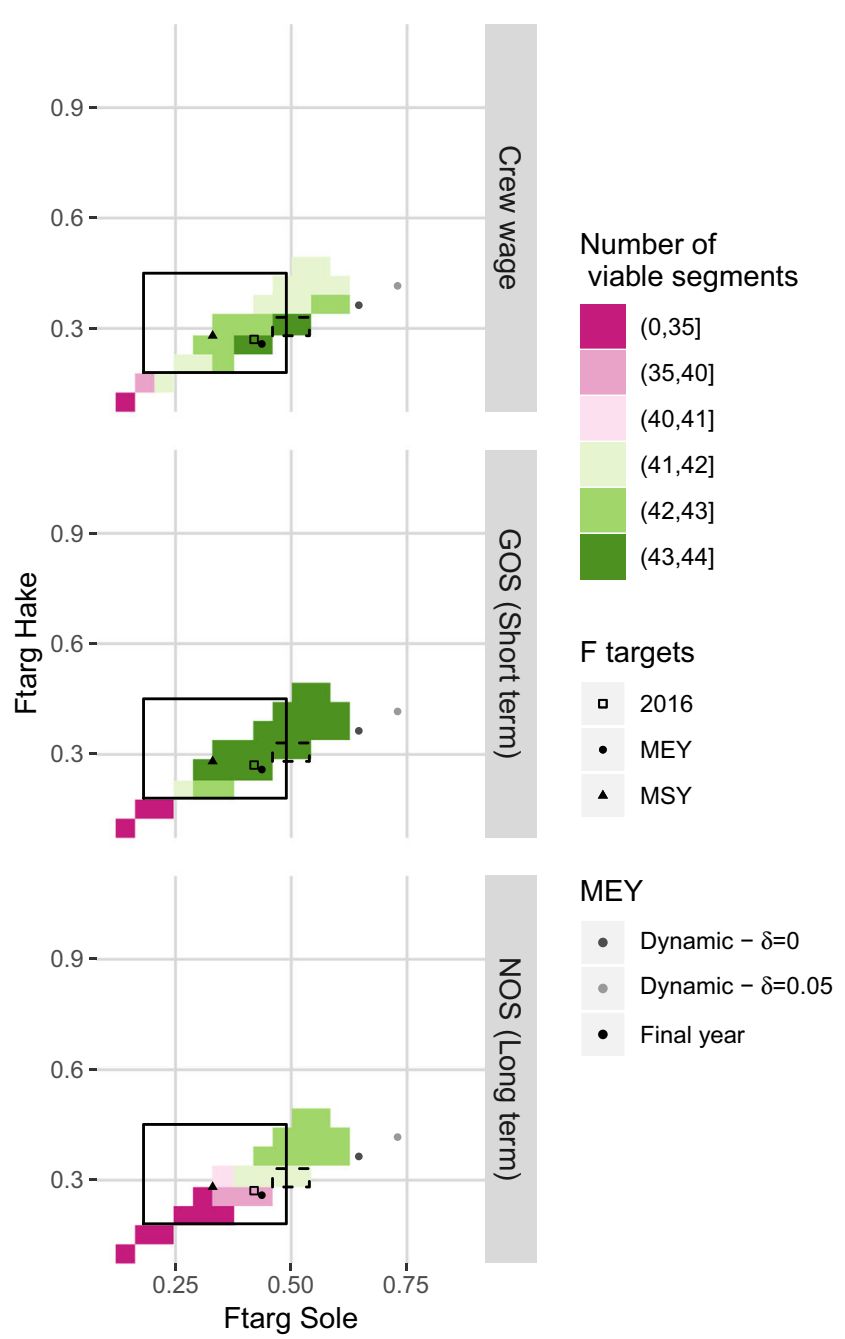

Fig. 5 Number of viable fishing segments regarding the 3 economic constraints: short-term viability, long-term viability and the ability to maintain fishing crews. The solid lined rectangle refers to the 2 species' $F_{\text {MSY }}$ ranges and the dashed lined rectangle shows the eco-viable space. Source: IAM model

profits at the end of the simulation period is lower than $F_{\text {MSY }}$ for hake but higher for sole.

\subsection{From Target Reference Points on Fishing Mortality to TAC Advice}

In particular, interest for decision-makers are the TACs associated with the recommended fishing mortality targets. Mean predicted TACs between 2017 and 2025 for sole and hake for some strategies are represented on Fig. 6. The eco-viability strategy corresponds to $F_{\text {targ }}$ HKE $=0.31$ and $F_{\text {targ }}=0.48$, and the dynamic MEY strategy is the dynamic MEY with a discount rate of $5 \%$.

On the first year that the harvest control rule applies, the higher the fishing mortality target, the greater the resulting TAC. However, this correlation inverts in the longer term as more conservative strategies lead to more abundant stocks, and hence higher TACs. In the case of sole and hake, benefits from short-term restrictions on fishing mortality targets can be expected after 5 to 6 years, when the less conservative strategy (dynamic MEY) starts resulting in lower TACs than more conservative ones. In the long term, all identified strategies result in higher TACs than in 2016 although some lead to lower catches in the short term (MSY for sole and MSY, status quo and final MEY for hake). In addition to these trends, inter-annual variations in TACs can also be quantified. In the status quo, MSY and final MEY strategies, year-to-year variations in TACs never exceeded $15 \%$, a threshold commonly requested by the fishing industry to stabilise catch possibilities in EU multi-annual management plans [66]. The dynamic MEY strategy, however, led to TACs on sole and hake respectively increasing by $66 \%$ and $31 \%$ between 2016 and 2017. In the eco-viability strategy, the TAC on sole increased by $22 \%$ in the first year of implementation (Table 2).

The eco-viability strategy features as an intermediate strategy, neither too conservative to ensure the economic viability of the greatest number of segments during the entire projection period, nor too bold, so as not to impede the reproductive capacity of any single stock. Consequently, it allows for catches to be maintained at quite high levels over time, without deviating too much from the MSY strategy. Indeed, at the end of the 10-year projection period, catches of sole and hake in the eco-viability strategy are expected to be respectively $95 \%$ and $97 \%$ of those in the MSY strategy. It is also the strategy with the second highest NPV, after the MEY strategy as shown in Table 2.

\section{Discussion}

\subsection{Towards Operational Eco-viable TAC Advice for Mixed Fisheries}

The approach presented here lays the foundations for more integrated advice for mixed fisheries under output controls.

First, it allows identifying the set of management strategies that are technically achievable in mixed fisheries with joint production. This is what we called the operating domain of the fishery, namely the set of fishing mortality targets ensuring that at least $95 \%$ of each TAC is consumed. Outside of this domain, quotas that are not fully consumed may create an incentive to continue fishing and discard over-quota catches of limiting species, undermining the monitoring and enforcement of catch regulations. The importance of limiting the mismatch between expected catches and TACs has also emerged in recent mixed fisheries advice [13]. The operating domain is case specific: it depends on the structure of the fleet, and on the selectivity 
Fig. 6 Time series of predicted TACs for identified strategies: single-species $F_{\mathrm{MSY}}$, Status quo $F_{2016}$, eco-viability, and MEY. Source: IAM model

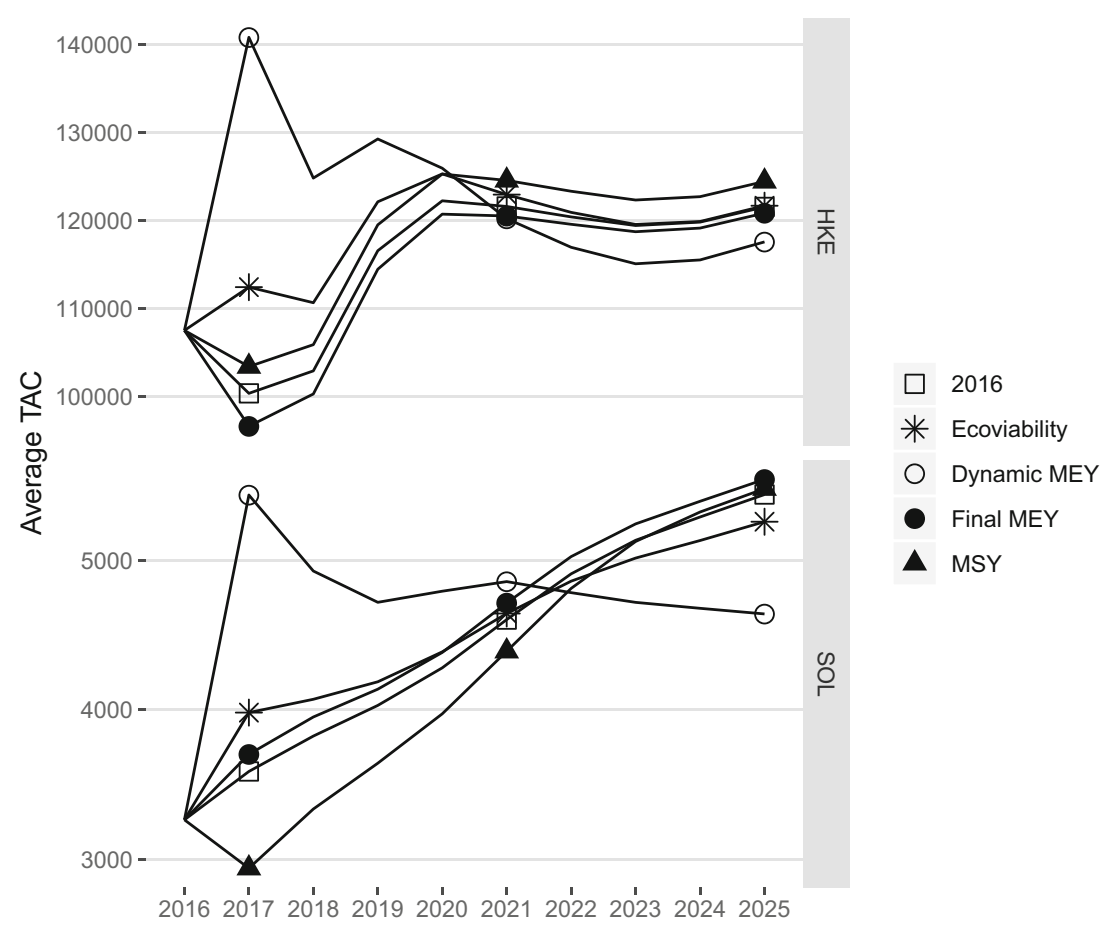

and catchability of the different metiers. Its extent will also depend on technical flexibilities: fisheries with productions which are joint in fixed proportions will show a narrower operating domain than fisheries with limited technical interactions. Flexibility offered by management can also broaden the operating space: in a system where individual quotas are tradeable, individual harvesters may have more possibilities to balance their catches with available quotas. Moreover, the operating domain can change over time as fishing practices may adapt to changes in incentives resulting from external economic drivers (e.g. changes in input costs or in demand and fish prices), regulations, ecological factors and technical change.

Second, the application of the eco-viability approach allows evaluating how alternative management strategies

Table 2 Summary table of selected strategies, compared in terms of the NPV of the hake and sole fisheries (calculated with a discount rate of 5\%) and the maximum inter-annual absolute TAC variation

\begin{tabular}{|c|c|c|c|c|}
\hline \multirow[t]{2}{*}{ Strategy } & \multicolumn{2}{|l|}{$F_{\text {targ }}$} & \multirow{2}{*}{$\begin{array}{l}\operatorname{Max} \\
\Delta \mathrm{TAC}(\%)\end{array}$} & \multirow{2}{*}{$\begin{array}{l}\mathrm{NPV} \\
(\mathrm{M} €)\end{array}$} \\
\hline & HKE & SOL & & \\
\hline 2016 & 0.27 & 0.42 & 13 & 25.2 \\
\hline Eco-viability & 0.30 & 0.48 & 22 & 26.9 \\
\hline Dynamic MEY & 0.36 & 0.65 & 66 & 28.6 \\
\hline Final MEY & 0.26 & 0.44 & 14 & 24.9 \\
\hline MSY & 0.28 & 0.33 & 13 & 24.2 \\
\hline
\end{tabular}

The dynamic MEY strategy maximises NPV at the 5\% discount rate perform in meeting predefined constraints, be they biological, economic or social. Those constraints are defined by thresholds on key variables of the model. Consequently, the type of constraints that can be accounted for in the evaluation will depend on the model's complexity. The present application considered a biological constraint applied to 4 stocks and 3 economic constraints (positive gross and net profits, and minimum crew wage) for the 44 fleets segments. Sustainability constraints could expand further upstream (e.g. preservation of the ecosystem's good environmental status) or downstream (e.g. ensuring the viability of the downstream fish supply chain), and range from fine-scale (e.g. ensure the economic viability of individual harvesters) to broad-scale (e.g. maintain global fish supplies) constraints. In the best case, management strategies that simultaneously meet all constraints can be identified and form what we called the eco-viable space. In remaining cases, the transparent evaluation of the strategies regarding the various constraints can still assist decision-makers in assessing trade-offs and identifying compromise strategies. It is important to highlight that increasing the number of constraints does not increase the computing time. However, it makes it more difficult to identify eco-viable management strategies.

Not only can the present framework help in the decision of management targets (here in the form of targeted fishing mortality) but it also provides the time series of TAC recommendations associated to those targets, thus giving more visibility to fishing firms and the opportunity to adjust their fishing strategies. 


\subsection{Its Application to the Bay of Biscay Demersal Mixed Fishery}

We were unable to identify management strategies ensuring that the viability constraints proposed for this application were simultaneously met by all stocks and all segments over the 10-year simulation period. This did not result from the biological constraint of maintaining all stocks above their limit biomass reference points. Rather, viability was undermined by a tension between the crews' and shipowners' interests. Indeed, generating sufficient profits to reach long-term economic viability implied harvesting stocks at a point where the labour productivity was too low to ensure the minimal FTE wage for the crews. In our analysis, the share rate was assumed constant but vessel owners have proven to adapt the crew share to external factors [67] in order to maintain their crew when profits are low and to increase their share when profits increase again. Considering such adaptive share rates in the model might resolve the observed trade-off between crew's and owner's surplus. In addition, imposing the average wage of a French seaman as a minimum requirement is actually more demanding than maintaining current standards. Therefore, a more accurate estimation of an acceptable remuneration threshold for the fishery might also make co-viable strategies emerge. Moreover, the possibility for individual vessels to alter their catch composition is limited in the current version of the model since metier catchabilities are considered constant and individual harvesters are assumed to fish as they did in the reference year. Allowing more flexibility in fishing effort allocation (e.g. with a coefficient $\alpha$ in Eq. 4 that is a weighted combination of profitability and tradition as suggested by [49]) will broaden the operating domain and possibly allow co-viable strategies to emerge. The extent to which joint productions can be altered in the Bay of Biscay demersal fishery has not been specifically investigated but insights from other fisheries show that given the right incentives fishers are often able to change their fishing practices to avoid undesirable catches [68-70].

We noted that single-species MSY reference points were achievable targets in the particular case of the hake and sole fishery in the Bay of Biscay. However, this result should not question the necessity to assess whether current management targets (by default $F_{\text {MSY }}$ for data-rich European stocks) are in line with technical limitations in other mixed fisheries or when more stocks are considered in the reconciliation process.

Maximising the net present value of the hake and sole fishery over the 10-year simulation period with a discount factor of $5 \%$ led to harvest rates well above those that maximise the fishery's net profits after 10 years. This shows that long-term gains from fishing at low harvest rates are offset by short-term profits from fishing at high harvest rates. The difference between dynamic and static MEY should decrease as the projection horizon increases since short-term profits will weigh less in the calculation of the NPV. Moreover, whereas the stock of hake reached equilibrium at the end of the simulation period as evidenced by TACs levelling-off in Fig. 6, the stock of sole was still in a transition phase. Consequently, harvest rates associated to MEY might also decrease with a longer projection horizon as long-term profits from fishing at low harvest rates are still expected to increase after 10 years. It is worth noting that maximising the fishery's net profits after 10 years requires to harvest hake below and sole above their respective $F_{\mathrm{MSY}}$ reference points. The fact that fisherywide reference points (multispecies MSY or MEY) can lead to the under- or over-exploitation of individual stocks has already been highlighted by many authors $[16,23,43,71$, 72]. Finally, we observed that the dynamic MEY is sensitive to the value of the discount rate, and, as expected, the higher the discount rate, the higher the associated harvest rates.

\subsection{Limitations and Perspectives}

In this work, we illustrated how to reconcile fishing mortality targets for two stocks at the heart of technical interactions, through the identification of operating and co-viable spaces that are displayable in two dimensions. Four main limitations of the approach warrant further research that was beyond the scope of the work presented here.

First, joint production in fisheries rarely is limited to two species. There is thus a need to generalise this approach to an unlimited number of stocks the catch of which technically interacts. Indeed, with operating and viable spaces dimensioned by the number of controls (here the number of stocks under TAC regulation), this methodology would quickly lack operationality for fisheries with more than three interacting stocks. The issue of dimensionality could be tackled through an optimised exploration of ecoviable strategies, similar to the approach developed by [34], rather than through the exhaustive screening of all possible controls as done here.

Second, as highlighted earlier, the operating and viability domains presented here are likely to be overly constrained by rigid assumptions on how fishers adapt to regulations, in the model. Enabling more dynamic effort and/or quota allocation and investigating whether this provides more room for viability will be the focus of future work.

Third, in highly diversified mixed fisheries, the issue of "secondary species" that are caught as by-catch when targeting more valuable species often arises. Many of these are considered data-limited stocks (DLS) for which the lack 
of data prevents the parameterisation of stock dynamics models. So far, the integration of those species in mixed fisheries bio-economic models has been inconsistent: some consider that their landings remain constant [43], some assume that their biomass remains constant and calculate catches using a Baranov production function [71] (which is equivalent to our constant LPUE hypothesis when the output elasticity for biomass in the Baranov equation equals 1), some scale the income from those species as a proportion of the revenue of the target species [34, 43, 73]. Different approaches to model the income derived from those species are likely to result in different economic outcomes for the modelled fleets, and ensuing viability evaluations. For instance, the income from stocks modelled with a constant LPUE will always increase with fishing effort and never show any stock effect. If this is the case, the income of fleets that mostly depend on those species may be overestimated under high fishing pressure (and conversely underestimated under low fishing pressure) which might wrongly bias the advice regarding harvest of the main stocks. Assuming the income associated to minor species is proportional to the income of the target species could resolve this bias, but is not straightforward to implement in fisheries like the mixed demersal fishery of the Bay of Biscay, where there is no unique target species. Progress in this space is likely to result from the systematic identification of the circumstances under which each approach bears more relevance, leading to model each species or group of species accordingly. For instance, as assumed in our analysis, a constant biomass of the stock is only-if at all, given natural variability-relevant if the modelled fleets do not account for much of the total landings of the stock, and thus to the fishing mortality exerted on the stock.

Finally, setting acceptability constraints should be the result of discussions with all stakeholders in the fishery, from fishers to consumers, fisheries managers, scientists, fish processors, harbour managers, etc. The involvement of stakeholders was beyond the scope of this work, more designed to be a proof of concept than actual alternative advice for the management of the Bay of Biscay demersal mixed fishery.

\subsection{Articulation with Current ICES Mixed Fisheries Advice}

The mixed fisheries working group (WGMIXFISH) at ICES has been developing the Fcube methodology to provide mixed fisheries TAC advice since 2009 [74], with first implementation in the North Sea demersal fishery in 2012 [75]. In its latest report, WGMIXFISH also extended its advice to the Celtic Sea and Iberian Waters mixed fisheries [75]. An application of the framework is also under way in the Bay of Biscay. The Fcube approach provides short-term mixed fisheries catch forecasts under different scenarios of quota uptake (e.g. fishers stop once they reach their most constraining quota, or once they have consumed all quotas), assuming constant metier catchabilities and effort allocation among metiers [7, 13, 75]. In the Fcube approach, biological sustainability is ensured a priori by restricting fishing mortalities to stock-specific MSY ranges, and economic viability is not assessed. Fcube is only used to provide short-term mixed fisheries catch forecasts. Regarding the issue of catch-quota imbalance, Fcube identifies the combination of fishing mortalities within the MSY ranges that minimises the difference in catches summed across all stocks between the "min" and "max" scenarios. In our approach, we assumed that fishers would stop fishing once they have reached their most constraining quota, which corresponds to the "min" scenario in the Fcube framework and the full implementation of the landing obligation. We also assumed constant catchabilities and effort allocation among metiers, but our projections were run over a 10-year period to assess the bio-economic viability of various harvest scenarios. Because intergenerational equity is an intrinsic feature of viability approach, the approach can be used to advise yearly tactical TAC decisions as well as to inform on longer term consequences of short-term decisions, which is the horizon at which sustainability must be assessed. We adopted a more exhaustive approach than in Fcube to the catch-quota imbalance question, by simulating all possible combinations and identifying the set of satisfying quota uptake where all quotas would be at least consumed by $95 \%$. We thus feel that the present approach could effectively be applied to other European fisheries with technical interactions based on an operating model parametrized with ICES stock assessment models and DCF fleets economic data.

Acknowledgements Authors would also like to thank the SIH Système d'Informations Halieutiques for providing data, and the two anonymous reviewers for their constructive comments on the previous version of the manuscript.

Responsibility for the results set out in this manuscript lies entirely with the authors.

Funding Information This work was supported by a public grant overseen by the French National Research Agency (ANR) as part of the "Investissements d'avenir" program (Reference : ANR-10-EQPX17 - Centre d'accès sécurisé aux données - CASD), the University of Tasmania (UTAS)/ Commonwealth Scientific and Industrial Research Organisation (CSIRO) PhD Program in Quantitative Marine Science and the French Research Institute for Exploitation of the Sea (Ifremer), the Ecole des Docteurs of University Bretagne Loire and the Conseil Régional de Bretagne.

Open Access This article is distributed under the terms of the Creative Commons Attribution 4.0 International License (http://creativecommons. org/licenses/by/4.0/), which permits unrestricted use, distribution, and reproduction in any medium, provided you give appropriate credit to the original author(s) and the source, provide a link to the Creative Commons license, and indicate if changes were made. 


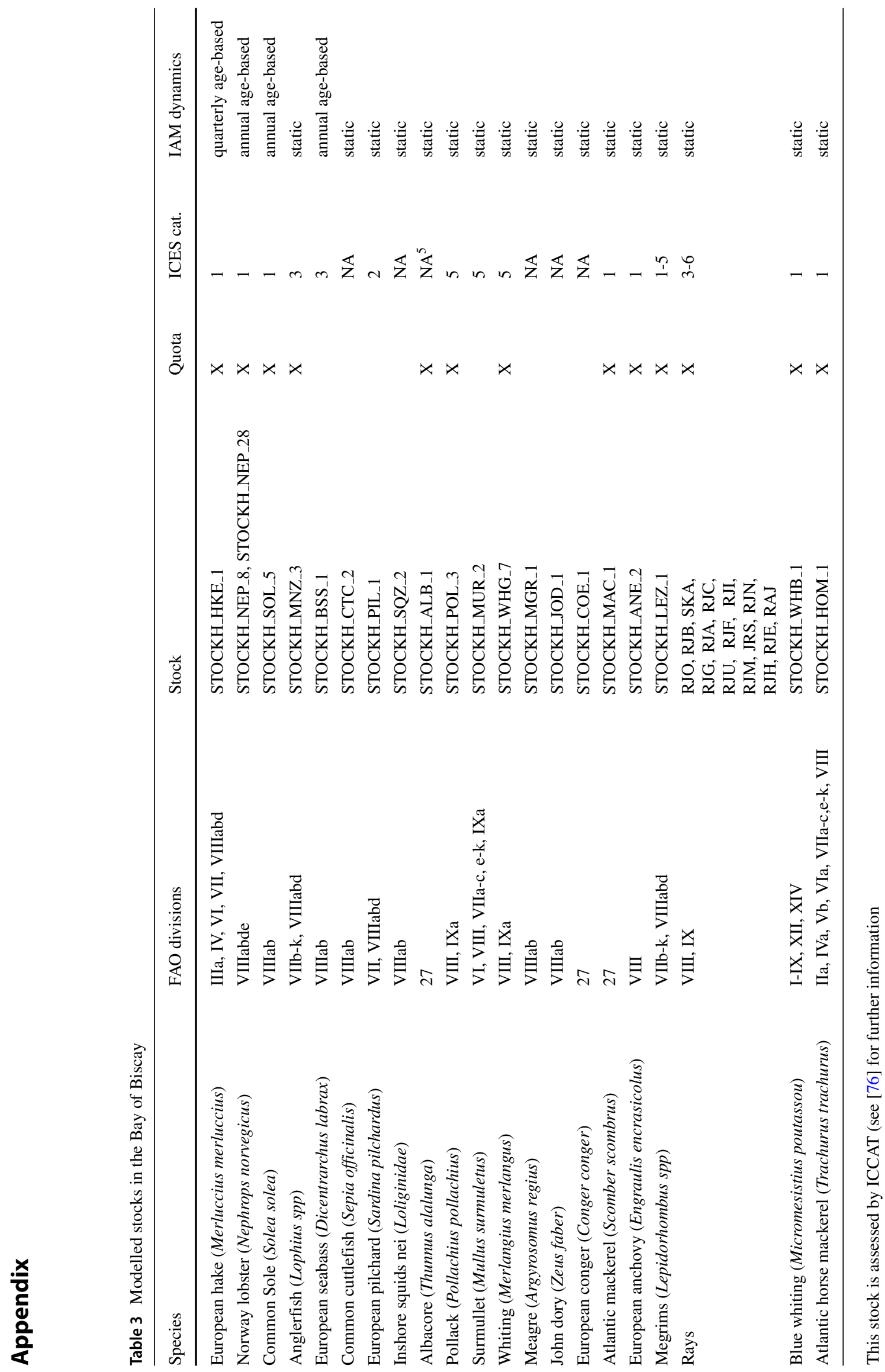


Table 4 List of metiers

\begin{tabular}{ll}
\hline Name & DCF code \\
\hline Demersal trawl Nephrops & OTBNEP, OTTNEP \\
Demersal trawl Sole & OTBSOX, OTTSOX \\
Demersal trawl Anglerfish & OTBMNZ, OTTMNZ \\
Demersal trawl Cephalopods & OTBSQU, OTTSQU, OTBCTL, OTTCT \\
Demersal trawl other species & OTTxxx, OTBxxx \\
Pelagic trawl other species & OTMxxx, PTMxxx \\
Danish Seine & SDNxxx \\
Net Sole & GTRSOX, GNSSOX \\
Net Hake & GNSHKE \\
Net other species & GNSxxx, GTSxxx \\
Longline Hake & LLSHKE \\
Longline other species & LLSxxx, LL_xxx \\
Other & All not mentionned above \\
\hline
\end{tabular}

\section{References}

1. García, S.M. (Ed.) (2003). The ecosystem approach to fisheries: issues, terminology, principles, institutional foundations, implementation and outlook. Number 443 in FAO Fisheries Technical Paper. Rome: Food and Agriculture Organization of the United Nations. ISBN 978-92-5-104960-0.

2. Pikitch, E.K. (July 2004). Ecosystem-based fishery management. Science, 305(5682), 346-347. ISSN 0036-8075, 1095-9203. https://doi.org/10.1126/science.1098222.

3. Pitcher, T.J., Kalikoski, D., Short, K., Varkey, D., Pramod, G. (2009). An evaluation of progress in implementing ecosystembased management of fisheries in 33 countries. Marine Policy, 33(2), 223-232. ISSN 0308597X. https://doi.org/10.1016/j. marpol.2008.06.002.

4. Link, J.S., \& Browman, H.I. (2017). Operationalizing and implementing ecosystem-based management. ICES Journal of Marine Science: Journal du Conseil, fsw247. ISSN 1054-3139, 1095-9289. https://doi.org/10.1093/icesjms/fsw247.

5. Schrope, M. (2010). Fisheries: what's the catch? Nature, 465(7298), 540-542. ISSN 0028-0836, 1476-4687. https://doi. org/10.1038/465540a.

6. Rijnsdorp, A., Daan, N., Dekker, W., Poos, J., Van Densen, W. (2007). Sustainable use of flatfish resources: addressing the credibility crisis in mixed fisheries management. Journal of Sea Research, 57(2-3), 114-125. ISSN 13851101. https://doi.org/10. 1016/j.seares.2006.09.003.

7. Ulrich, C., Reeves, S.A., Vermard, Y., Holmes, S.J., Vanhee, W. (2011). Reconciling single-species TACs in the North Sea demersal fisheries using the Fcube mixed-fisheries advice framework. ICES Journal of Marine Science, 68(7), 1535-1547. ISSN 1054-3139, 1095-9289. https://doi.org/10.1093/icesjms/fsr060.

8. ICES (2015). Report of the working group on mixed fisheries advice methodology (WGMIXFISH-METH). ICES document CM 2015/ACOM. DTU -Aqua, Charlottenlund, Denmark.

9. EU (2013). Regulation (EU) No 1380/2013 of the European Parliament and of the Council of 11 December 2013 on the Common Fisheries Policy amending Council Regulations (EC) No 1954/2003 and (EC) No 1224/2009 and repealing Council Regulations (EC) No 2371/2002 and (EC) No 39/2004 and Council Decision 2004/585/EC.

10. Simons, S.L., Döring, R., Temming, A. (2015). Modelling fishers' response to discard prevention strategies: the case of the North Sea saithe fishery. ICES Journal of Marine Science, 72(5), 1530-1544. ISSN 1095-9289, 1054-3139. https://doi.org/10.1093/icesjms/fsu229.

11. Prellezo, R., Carmona, I., García, D. (2016). The bad, the good and the very good of the landing obligation implementation in the Bay of Biscay: a case study of Basque trawlers. Fisheries Research, 181, 172-185. ISSN 01657836. https://doi.org/10.1016/j.fishres. 2016.04.016.

12. EU (2014). Task Force on multiannual plans. Final report.

13. Ulrich, C., Vermard, Y., Dolder, P.J., Brunel, T., Jardim, E., Holmes, S.J., Kempf, A., Mortensen, L.O., Poos, J.-J. (2017). Rindorf, A. Achieving maximum sustainable yield in mixed fisheries: a management approach for the North Sea demersal fisheries. ICES Journal of Marine Science, 74(2), 566-575. ISSN 1054-3139, 1095-9289. https://doi.org/10.1093/icesjms/fsw 126.

14. DAFF (2007). Commonwealth fisheries harvest strategy: Policy and guidelines.

15. Pascoe, S., Hutton, T., Thébaud, O., Deng, R., Klaer, N., Vieira, S. (2015). Setting economic target reference points for multiple species in mixed fisheries. FRDC Final Report, CSIRO Oceans and Atmosphere Flagship.

16. Hoshino, E., Pascoe, S., Hutton, T., Kompas, T., Yamazaki, S. (2018). Estimating maximum economic yield in multispecies fisheries: a review. Reviews in Fish Biology and Fisheries, 28(2), 261-276. ISSN 0960-3166, 1573-5184. https://doi.org/10.1007/ s11160-017-9508-8.

17. Martinet, V., Thébaud, O., Rapaport, A. (2010). Hare or tortoise? Trade-offs in recovering sustainable bioeconomic systems. Environmental Modeling \& Assessment, 15(6), 503-517. ISSN 14202026, 1573-2967. https://doi.org/10.1007/s10666-010-9226-2.

18. EU (2009) GREEN PAPER - reform of the common fisheries policy.

19. Villasante, S., Do Carme garcía-negro, M., González-laxe, F., Rodríguez, G.R. (2011). Overfishing and the common fisheries policy: (un)successful results from TAC regulation?: overfishing and the common fisheries policy. Fish and Fisheries, 12(1), 3450. ISSN 14672960. https://doi.org/10.1111/j.1467-2979.2010. 00373.x.

20. Carpenter, G., Kleinjans, R., Villasante, S., O'leary, B.C. (2016). Landing the blame: the influence of EU Member States on quota setting. Marine Policy, 64, 9-15. ISSN 0308597X. https://doi.org/10.1016/j.marpol.2015.11.001.

21. ICES (2014). ICES Strategic Plan 2014-2018. 
22. ICES (2016). Report of the Workshop on DEveloping Integrated AdviCE for Baltic Sea ecosystem-based fisheries management (WKDEICE). Technical report ICES CM 2016/SSGIEA:13. Helsinki, Finland.

23. Voss, R., Quaas, M.F., Stoeven, M.T., Schmidt, J.O., Tomczak, M.T., Möllmann, C. (2017). Ecological-economic fisheries management advice-quantification of potential benefits for the case of the eastern Baltic COD fishery. Frontiers in Marine Science, 4. ISSN 2296-7745. https://doi.org/10.3389/fmars.2017.00209.

24. Aubin, J.P. (1991). Viability Theory. Boston: systems \& control. Birkhauser. ISBN 978-0-8176-3571-8 978-3-7643-3571-7.

25. Aubin, J.-P., Bayen, A.M., Saint-Pierre, P. (2011). Viability theory new directions. Berlin: Springer. ISBN 978-3-642-16683-9 9783-642-16684-6. https://doi.org/10.1007/978-3-642-16684-6.

26. Oubraham, A., \& Zaccour, G. (2018). A survey of applications of viability theory to the sustainable exploitation of renewable resources. Ecological Economics, 145, 346-367. ISSN 09218009. https://doi.org/10.1016/j.ecolecon.2017.11.008.

27. Martinet, V., \& Doyen, L. (2007). Sustainability of an economy with an exhaustible resource: a viable control approach. Resource and Energy Economics, 29(1), 17-39. ISSN 09287655. https://doi.org/10.1016/j.reseneeco.2006.03.003.

28. Doyen, L., \& Martinet, V. (2012). Maximin, viability and sustainability. Journal of Economic Dynamics and Control, 36(9), 1414-1430. ISSN 01651889. https://doi.org/10.1016/j.jedc.2012. 03.004.

29. De Lara, M., Martinet, V., Doyen, L. (2015). Satisficing versus optimality criteria for sustainability. Bulletin of Mathematical Biology, 77(2), 281-297. ISSN 0092-8240, 1522-9602. https://doi.org/10.1007/s11538-014-9944-8.

30. Rindorf, A., Dichmont, C.M., Levin, P.S., Mace, P., Pascoe, S., Prellezo, R., Punt, A.E., Reid, D.G., Stephenson, R., Ulrich, C., Vinther, M., Clausen, L.W. (2016). Food for thought pretty good multispecies yield. ICES Journal of Marine Science: Journal du Conseil, fsw071. ISSN 1054-3139, 1095-9289. https://doi.org/10.1093/icesjms/fsw071.

31. Béné, C., Doyen, L., Gabay, D. (2001). A viability analysis for a bio-economic model. Ecological Economics, 36(3), 385-396. ISSN 09218009. https://doi.org/10.1016/S0921-8009(00)00261-5.

32. Cissé, A., Gourguet, S., Doyen, L., Blanchard, F., Péreau, J.C. (2013). A bio-economic model for the ecosystem-based management of the coastal fishery in French Guiana. Environment and Development Economics, 18(03), 1469-4395. ISSN 1355770X. https://doi.org/10.1017/S1355770X13000065.

33. Cissé, A., Doyen, L., Blanchard, F., Béné, C., Péreau, J.-C. (2015). Ecoviability for small-scale fisheries in the context of food security constraints. Ecological Economics, 119, 39-52. ISSN 09218009. https://doi.org/10.1016/j.ecolecon.2015.02.005.

34. Gourguet, S., Macher, C., Doyen, L., Thébaud, O., Bertignac, M., Guyader, O. (2013). Managing mixed fisheries for bio-economic viability. Fisheries Research, 140, 46-62. ISSN 01657836. https://doi.org/10.1016/j.fishres.2012.12.005.

35. Gourguet, S., Thébaud, O., Jennings, S., Little, L.R., Dichmont, C.M., Pascoe, S., Deng, R.A., Doyen, L. (2016). The cost of coviability in the Australian northern prawn fishery. Environmental Modeling \& Assessment, 21(3), 1573-2967. ISSN 1420-2026. https://doi.org/10.1007/s10666-015-9486-y.

36. Symes, D., \& Phillipson, J. (2009). Whatever became of social objectives in fisheries policy? Fisheries Research, 95(1), 1-5. ISSN 01657836. https://doi.org/10.1016/j.fishres.2008.08.001.

37. Nielsen, J.R., Thunberg, E., Holland, D.S., Schmidt, J.O., Fulton, E.A., Bastardie, F., Punt, A.E., Allen, I., Bartelings, H., Bertignac, M., Bethke, E., Bossier, S., Buckworth, R., Carpenter, G., Christensen, A., Christensen, V., Da-Rocha, J.M., Deng, R., Dichmont, C., Doering, R., Esteban, A., Fernandes, J.A.,
Frost, H., Garcia, D., Gasche, L., Gascuel, D., Gourguet, S., Groeneveld, R.A., Guillén, J., Guyader, O., Hamon, K.G., Hoff, A., Horbowy, J., Hutton, T., Lehuta, S., Little, L.R., Lleonart, J., Macher, C., Mackinson, S., Mahevas, S., Marchal, P., MatoAmboage, R., Mapstone, B., Maynou, F., Merzéréaud, M., Palacz, A., Pascoe, S., Paulrud, A., Plaganyi, E., Prellezo, R., van Putten, E.I., Quaas, M., Ravn-Jonsen, L., Sanchez, S., Simons, S., Thébaud, O., Tomczak, M.T., Ulrich, C., van Dijk, D., Vermard, Y., Voss, R., Waldo, S. (2018). Integrated ecologicaleconomic fisheries models-evaluation, review and challenges for implementation. Fish and Fisheries, 19(1), 1-29. ISSN 14672960. https://doi.org/10.1111/faf.12232.

38. Hilborn, R. (2007). Managing fisheries is managing people: what has been learned?. Fish and Fisheries, 8(4), 285-296. ISSN 14672960, 1467-2979. https://doi.org/10.1111/j.1467-2979.2007.002 63_2.x.

39. Fulton, E.A., Smith, A.D.M., Smith, D.C., van Putten, I.E. (2011). Human behaviour: the key source of uncertainty in fisheries management: human behaviour and fisheries management. Fish and Fisheries, 12(1), 2-17. ISSN 14672960. https://doi.org/10.1111/j.1467-2979.2010.00371.x.

40. EU (2018). Proposal for a regulation of the European Parliament and of the Council establishing a multiannual plan for fish stocks in the Western Waters and adjacent waters, and for fisheries exploiting those stocks, amending Regulation (EU) 2016/1139 establishing a multiannual plan for the Baltic Sea, and repealing Regulations (EC) No 811/2004, (EC) No 2166/2005, (EC) No 388/2006 (EC) 509/2007 and (EC) 1300/2008.

41. Larabi, Z., Guyader, O., Macher, C., Daurès, F. (2013). Quota management in a context of non-transferability of fishing rights the French case study. Ocean \& Coastal Management, 84, 13-22. ISSN 09645691. https://doi.org/10.1016/j.ocecoaman.2013.07. 001.

42. DPMA and SIH, I (2018). Traitement des données Ifremer Système d'Informations Halieutiques.

43. Guillen, J., Macher, C., Merzéréaud, M., Bertignac, M., Fifas, S., Guyader, O. (2013). Estimating MSY and MEY in multi-species and multi-fleet fisheries, consequences and limits: an application to the Bay of Biscay mixed fishery. Marine Policy, 40, 64-74. ISSN 0308597X. https://doi.org/10.1016/j.marpol.2012.12.029.

44. Bellanger, M., Macher, C., Merzéréaud, M., Guyader, O., Le Grand, C. (2017). Investigating trade-offs in alternative catch share systems: an individual-based bio-economic model applied to the Bay of Biscay sole fishery. Canadian Journal of Fisheries and Aquatic Sciences, 1-17. ISSN 0706-652X, 1205-7533. https://doi.org/10.1139/cjfas-2017-0075.

45. Quillérou, E., \& Guyader, O. (2012). What is behind fleet evolution: a framework for flow analysis and application to the French Atlantic fleet. ICES Journal of Marine Science, 69(6), 1069-1077. ISSN 1095-9289, 1054-3139. https://doi.org/10.1093/icesjms/ fss060.

46. Macher, C., Bertignac, M., Guyader, O., Frangoudes, K., Frésard, M., Le Grand, C., Merzéréaud, M., Thébaud, O. (2018). The role of technical protocols and partnership engagement in developing a decision support framework for fisheries management. Journal of Environmental Management, 223, 503-516. ISSN 03014797. https://doi.org/10.1016/j.jenvman.2018.06.063.

47. Raveau, A., Macher, C., Méhault, S., Merzereaud, M., Le Grand, C., Guyader, O., Bertignac, M., Fifas, S., Guillen, J. (2012). A bio-economic analysis of experimental selective devices in the Norway lobster ( Nephrops norvegicus ) fishery in the Bay of Biscay. Aquatic Living Resources, 25(3), 1765-2952. ISSN 0990-7440. https://doi.org/10.1051/alr/2012035.

48. Punt, A.E., Butterworth, D.S., de Moor, C.L., De Oliveira, J.A.A., Haddon, M. (2016). Management strategy evaluation Best 
practices. Fish and Fisheries, 17(2), 303-334. ISSN 14672960. https://doi.org/10.1111/faf.12104.

49. Marchal, P., De Oliveira, J.A., Lorance, P., Baulier, L., Pawlowski, L. (2013). What is the added value of including fleet dynamics processes in fisheries models? Canadian Journal of Fisheries and Aquatic Sciences, 70(7), 992-1010. ISSN 0706-652X, 1205-7533. https://doi.org/10.1139/cjfas-2012-0326.

50. Girardin, R., Hamon, K.G., Pinnegar, J., Poos, J.J., Thébaud, O., Tidd, A., Vermard, Y., Marchal, P. (2017). Thirty years of fleet dynamics modelling using discrete-choice models: what have we learned? Fish and Fisheries, 18(4), 638-655. ISSN 14672960. https://doi.org/10.1111/faf.12194.

51. Thébaud, O., Ellis, N., Little, L.R., Doyen, L., Marriott, R.J. (2014). Viability trade-offs in the evaluation of strategies to manage recreational fishing in a marine park. Ecological Indicators, 46, 59-69. ISSN 1470160X. https://doi.org/10.1016/j.ecolind. 2014.05.013.

52. ICES (2015). ICES advice. Technical report, ICES.

53. Service de la Statistique et de la Prospective (2016). Enquête sur la production de données économiques dans le secteur des pêches maritimes.

54. De Lara, M., \& Doyen, L. (2008). Sustainable management of natural resources: mathematical models and methods. Environmental Science and Engineering Environmental Science. Berlin: Springer. ISBN 978-3-540-79073-0 978-3-540-79074-7. OCLC: 263412377

55. EU (2008). Commission Decision (2008/949/EC) of 6 November 2008 adopting a multiannual Community programme pursuant to Council Regulation (EC) No 199/2008 establishing a Community framework for the collection management and use of data in the fisheries sector and support for scientific advice regarding the Common Fisheries Policy.

56. ICES (2018). Eurostat/ICES data compilation of catch statistics.

57. ICES (2017). Report of the Working Group for the Bay of Biscay and Iberian waters Ecoregion (WGBIE). Technical report ICES CM 2017/ACOM:12. Cadiz, Spain.

58. Darby, C., \& Flatman, S. (1994). Virtual population analysis: Version 3.1 (Windows/Dos) user guide.

59. Shepherd, J. (1999). Extended survivors analysis an improved method for the analysis of catch-at-age data and abundance indices. ICES Journal of Marine Science, 56(5), 584-591. ISSN 10543139. https://doi.org/10.1006/jmsc.1999.0498.

60. ICES (2014). Report of the workshop to consider reference points for all stocks (WKMSYREF2). Technical report ICES CM 2014/ACOM:47, ICES HQ. Copenhagen, Denmark.

61. ICES (2016a). Sole (Solea solea) in divisions 8.a-b (northern and central Bay of Biscay). https://doi.org/10.17895/ices.pub.3236.

62. Stock Annex, I.C.E.S. (2018). Seabass (Dicentrarchus labrax) in division $8 \mathrm{ab}$ (Bay of Biscay). Technical report.

63. ICES (2016). Hake (Merluccius merluccius) in subareas 4, 6, and 7, and in divisions 3.a, 8.a-b, and 8.d, Northern stock (Greater North Sea, Celtic Seas, and the northern Bay of Biscay). https://doi.org/10.17895/ices.pub.3134.

64. Varian, H.R. (2010). Intermediate microeconomics: a modern approach, 8th edn. New York: W.W. Norton \& Co. ISBN 978-0393-93424-3. OCLC: ocn317920200.
65. ICES (2015). Report of the workshop to consider FMSY ranges for stocks in ICES categories 1 and 2 in Western Waters (WKMSYREF4). Technical Report ICES CM 2015/ACOM: 58.

66. Penas, E. (2007). The fishery conservation policy of the European Union after 2002: towards long-term sustainability. ICES Journal of Marine Science, 64(4), 1054-3139. ISSN 10959289. https://doi.org/10.1093/icesjms/fsm053.

67. Guillen, J., Boncoeur, J., Carvalho, N., Frangoudes, K., Guyader, O., Macher, C., Maynou, F. (2017). Remuneration systems used in the fishing sector and their consequences on crew wages and labor rent creation. Maritime Studies, 16(1). ISSN 2212-9790. https://doi.org/10.1186/s40152-017-0056-6.

68. Abbott, J.K., Haynie, A.C., Reimer, M.N. (2015). Hidden flexibility institutions, incentives, and the margins of selectivity in fishing. Land Economics, 91(1), 169-195. ISSN 0023-7639, 1543-8325. https://doi.org/10.3368/le.91.1.169.

69. Little, A.S., Needle, C.L., Hilborn, R., Holland, D.S., Marshall, C.T. (2015). Real-time spatial management approaches to reduce bycatch and discards: experiences from Europe and the United States. Fish and Fisheries, 16(4), 576-602. ISSN 14672960. https://doi.org/10.1111/faf.12080.

70. Reimer, M.N., Abbott, J.K., Wilen, J.E. (2017). Fisheries production management institutions, spatial choice, and the quest for policy invariance. Marine Resource Economics, 32(2), 143168. ISSN 0738-1360, 2334-5985. https://doi.org/10.1086/690 678.

71. García, D., Prellezo, R., Sampedro, P., Da-Rocha, J.M., Castro, J., Cerviño, S., García-Cutrín, J., Gutiérrez, M.-J. (2016). Bioeconomic multistock reference points as a tool for overcoming the drawbacks of the landing obligation. ICES Journal of Marine Science Journal du Conseil, fsw030. ISSN 1054-3139, 10959289. https://doi.org/10.1093/icesjms/fsw030.

72. Tromeur, E., \& Doyen, L. (2018). Optimal harvesting policies threaten biodiversity in mixed fisheries. Environmental Modeling \& Assessment, ISSN 1420-2026, 1573-2967. https://doi.org/10.1007/s10666-018-9618-2.

73. Ulrich, C., Pascoe, S., Sparre, P.J., Wilde, J.-W.D., Marchal, P. (2002). Influence of trends in fishing power on bioeconomics in the North Sea flatfish fishery regulated by catches or by effort quotas. Canadian Journal of Fisheries and Aquatic Sciences, 59(5), 829-843. ISSN 0706-652X, 1205-7533. https://doi.org/10.1139/f02-057.

74. ICES (2009). Report of the workshop on mixed fisheries advice for the North Sea. Technical Report CM 2009\ACOM:47, ICES. Copenhagen, Denmark.

75. ICES (2017). Report of the working group on mixed fisheries advice (WGMIXFISH-ADVICE). Technical Report CM 2017/ACOM:18, ICES. Copenhagen, Denmark.

76. ICCAT (2017). Report of the 2017 ICCAT Albacore Species group intersessional meeting (including assessment of Mediterranean Albacore). SCRS 2017/08, ICCAT. Madrid.

Publisher's Note Springer Nature remains neutral with regard to jurisdictional claims in published maps and institutional affiliations. 